\title{
Analyzing the Performance of MGNREGA Scheme using Data Mining Technique
}

\author{
G. Sugapriyan \\ M.Phil (CS) Research Scholar \\ SCSVMV University \\ Enathur, Kanchipuram.
}

\author{
S. Prakasam, Ph.D \\ Head of the Department \& Associate Professor \\ Department of CSA, \\ SCSVMV University \\ Enathur, Kanchipuram.
}

\begin{abstract}
Mahatma Gandhi National Rural Employment Guarantee Act (MGNREGA) is one of the schemes implemented by the government of India in keeping mind that "The soul of India lives in its villages", Most of the people in the rural part of the country are depending on the unskilled manual works for their survival. Many works have been done early in the process of criticizing the positive and negative impacts of this scheme. All works has some limitations such as it lack in the intelligent prediction, and to use suitable technique for the research, that motivates me to take up this specific scheme. This work is analyzing the Success of MGNREGA in Kanchipuram District, using Data Mining Technique along with the comparison of previous year statistic data provided by the government. The aim of this work is to analyze the performance and success of this scheme.
\end{abstract}

\section{General Terms}

Data mining, MGNREGA

\section{Keywords}

Classification, J48, Navie bayes, ZeroR, Rank Search

\section{INTRODUCTION}

Majority of population in India comes under rural area. The Government has announced so many schemes for rural masses with the aim to bring them out of the folder of poverty. Mahatma Gandhi National Rural Employment Guarantee Act (MGNREGA) is a pioneer scheme for providing minimum 100 days of job to the rural and tribal population, whose livelihood solely depends on the daily wages. Family members residing in the same village whose age is above 18 has to enroll themselves in the job card, for registering themselves in this scheme. Each micro family is provided with a unique job card. After the registration they'll get work within 15 days, else unemployment allowance has to be provided.

\section{RELATED WORKS}

Many works has been carried out in previous years to study and analyze the success and failure of this scheme. Different methods has been adapted by different authors, each has its own advantages and disadvantages.

Analyzing of MGNREGA scheme is a bit tricky work, because so many factors are involved to be considered. Some of the previous works carried out are presented in this section.

1] S. Krishnan et al [2014] [1] analyses this scheme as a India's policy and programme to eradicate poverty by 2015 . Since there are some problems, this is the most successful programme to eradicate poverty in India. It provides money directly in the hands of poor, especially women without any middlemen. This scheme creates visible and invisible effects on women and their saving capacity is increased. Majority of women workers are now able to participate in social activities.

2] Soumya Mohanty [2012] [2] study says that MGNREGA is a good scheme for eradicating unemployment and poverty, and how this scheme has provided alternative source of livelihood which reduces the migration, and makes rural people in villages self sustained. This study examines the impact created in the tribal livelihoods and to what extent this scheme provides justice in developing the livelihoods of poor tribal people in sundargarh district, Odisha. The result of this study shows that a small amount of impact has been created on tribal livelihoods. The core concept of the programme is ruined by its wrong implementation method. This study pointed out that major hurdles for this programme are religion, street biasness, improper co-ordination and defective leadership.

3] Jyoti poonia [2012] [3] this study shows that how most of the schemes until 90's in India concentrates on the organized sector. MGNREGA stands out of all the previous schemes because it potentially covers the whole country to provide a minimum income for household and also stimulates the local development. Initial findings shows that there has been shift out agriculture in the MGNREGA in Kerala, mainly in respect of women workers; many new persons are started to work under this scheme. This study shows that this scheme has the potential to stimulate the local development and labour market.

4] Abhishek Thakur[2011] [4] The objective of this study is to understand the source of livelihood and impact of this scheme in Seoni District of Madhya Pradesh. This study also tries to understand the daily changing private wage rate due to the implementation of MGNREGA and compare it to the time before the implementation of the scheme. In addition to this, it also attempts to find the change in relationship between labourers and formers by the impact of MGNREGA. The study shows that private wage has been increased, agriculture pattern has changed and relationship between labourers and formers has been altered by the implementation of MGNREGA.

5] Vikas Chaurasia [2014] [5] study shows that many information's are hidden in the data available in various fields which can be converted into valuable information and knowledge. It is a complicate process to find the meaningful information from it. Data mining is a important method for doing this kind of process. In the recent years, detecting breast cancer using data mining is one of the important research topics taken for research purpose. For calculating the outcome or to analyze the behavior of tumor the breast cancer classification data can be used. It compares three decision trees, for interpreting the result. 


\section{PERFORMANCE ANALYSIS OF MGNREGA SCHEME}

The effectiveness of MGNREGA scheme is analyzed in two ways, the first one is using the Data mining technique and the next method is via comparison of previous year statistical data. Data mining based MGNREGA analysis uses various algorithms to analyze this scheme. Here we analyze the progress of this scheme by comparing its last 3 year performance. Each financial year is taken in to consideration for the analysis.

\subsection{Population and Study}

Data used in this analysis are collected through questionnaire from survey conducted among MGNREGA workers in Kanchipuram, Walajabad and Uthiramerur blocks located in Kanchipuram District. A total population of 380 people is participated and 369 correctly answered questionnaires were taken for the process of data mining.

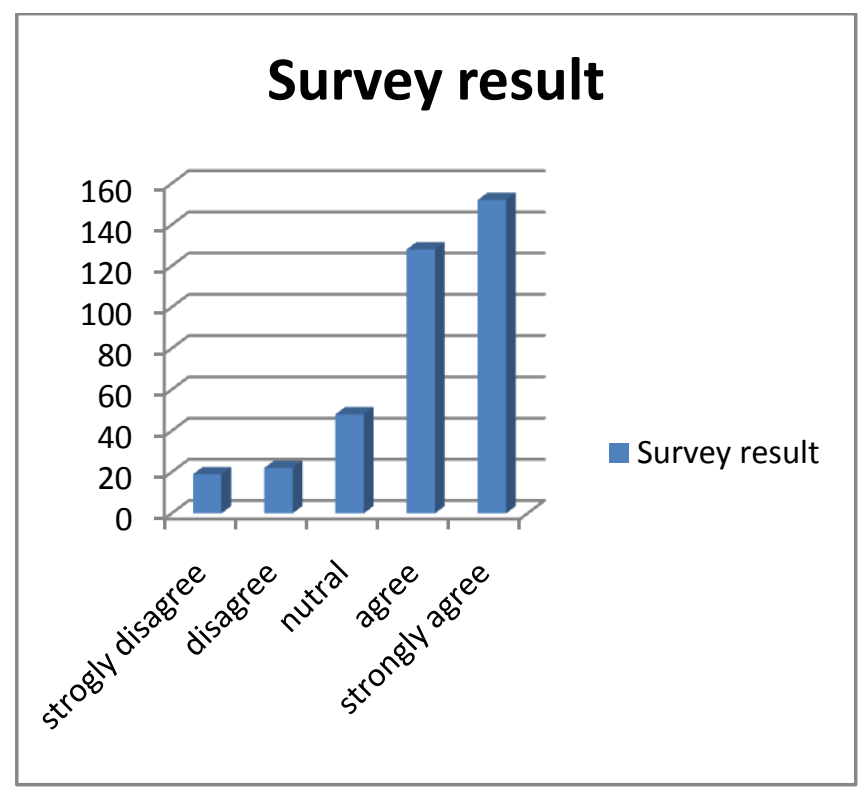

Fig 1.1 Feedback from users

\subsection{Analysis of MGNREGA using WEKA}

Waikato Environment for Knowledge Learning is the formal name for WEKA. It supports to carryout various data mining task such as data pre-processing, Clustering, Classification, Visualization, Regression and Feature Selection. WEKA is readily available under GNU general public license agreement. This software can be installed in as many systems as you like and it also can be redistributed and modified according to the user needs. Initially WEKA is written using $\mathrm{C}$ language, and then it is completely rewritten in Java. It has a user friendly environment with graphical interface that allows you to operate quickly on the data.

Here three data mining techniques are used for predicting the performance of MGNREGA scheme. They are Navie bayes, Zeror and Decision tree.

\subsubsection{Navie bayes}

Navie bayes is a well known and simple method, for performing supervised learning in a classification problem. It assumes that the value of a specific feature is un-related to the presence/absence of any other feature, given the class variable. The major advantage is only a small amount of training data is required to estimate the parameters for making the necessary classification.

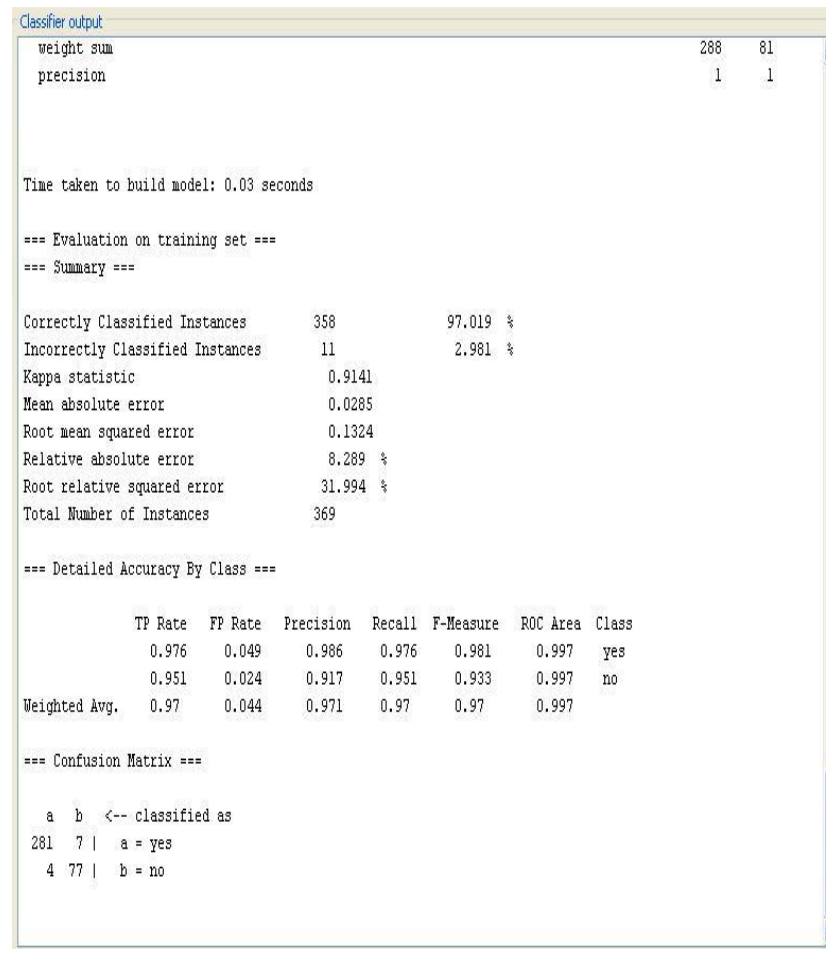

Fig 1.2 Navie bayes result

\subsubsection{Decision tree}

For classification problem decision tree is one of the popular algorithms. Rules are extracted from the training data set in decision tree to form a tree structure, and this rule is applied to the testing data. Here we took J48 algorithm for the purpose of classification. It recursively classifies until the data has been perfectly classified. With the smaller dataset this method gives maximum accuracy on training data.

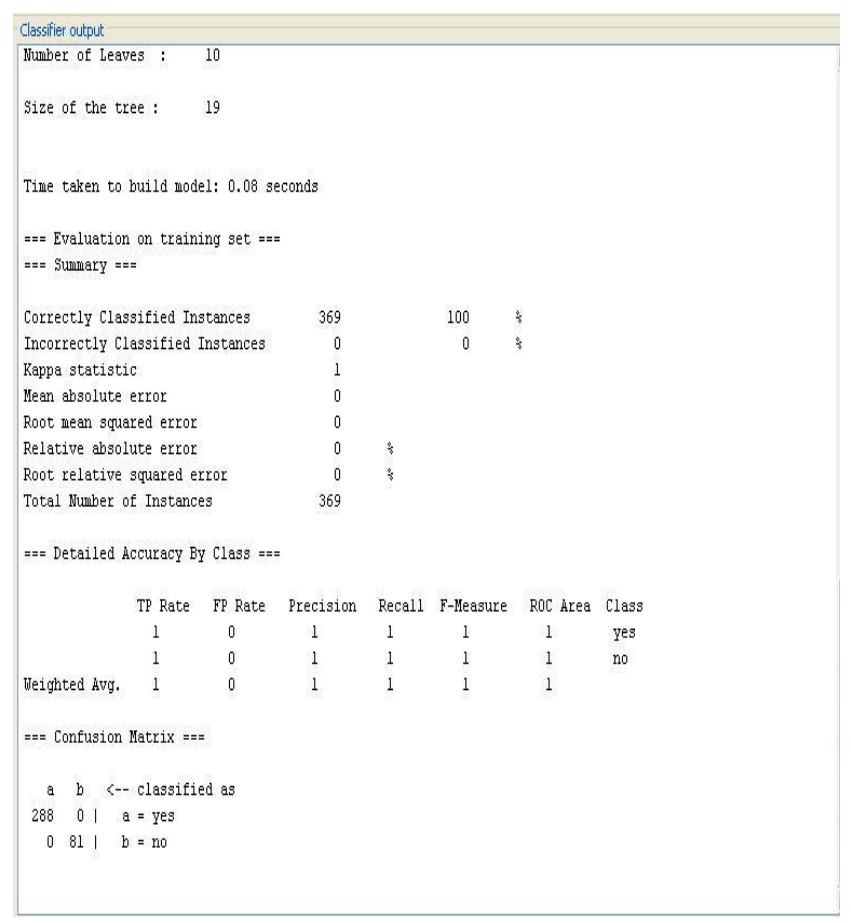

Fig 1.3 J48 Tree result 


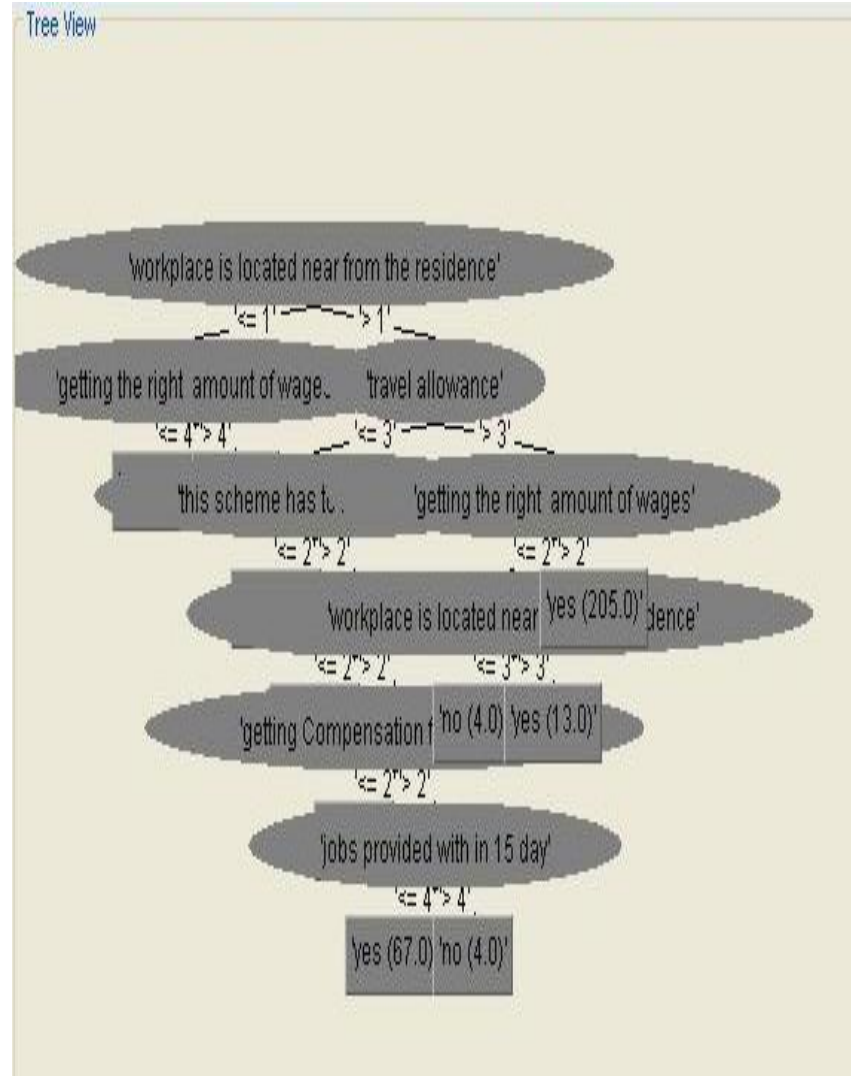

Fig 1.4 J48 Tree View

\subsubsection{Zeror}

This is the simplest method which depends on the target and ignores all predictors for the classification method. ZeroR classifier simply predicts the majority category (class). It is very useful for mapping a baseline performance as a benchmark for other classification methods.

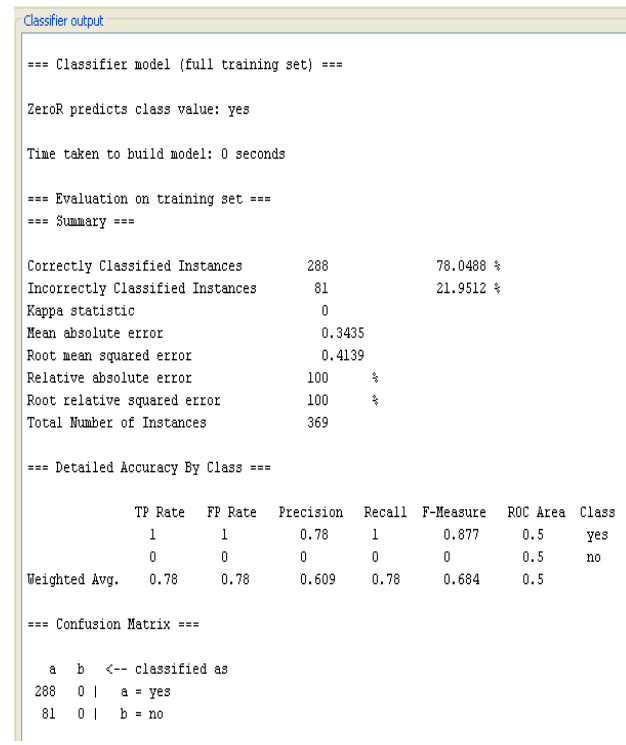

Fig 1.5 ZeroR result

\subsubsection{Rank search}

Rank search is used for assigning the rank in order that the influence plays a major role in the success of the scheme. It analyses all the factors and list the influencing factor in an order.

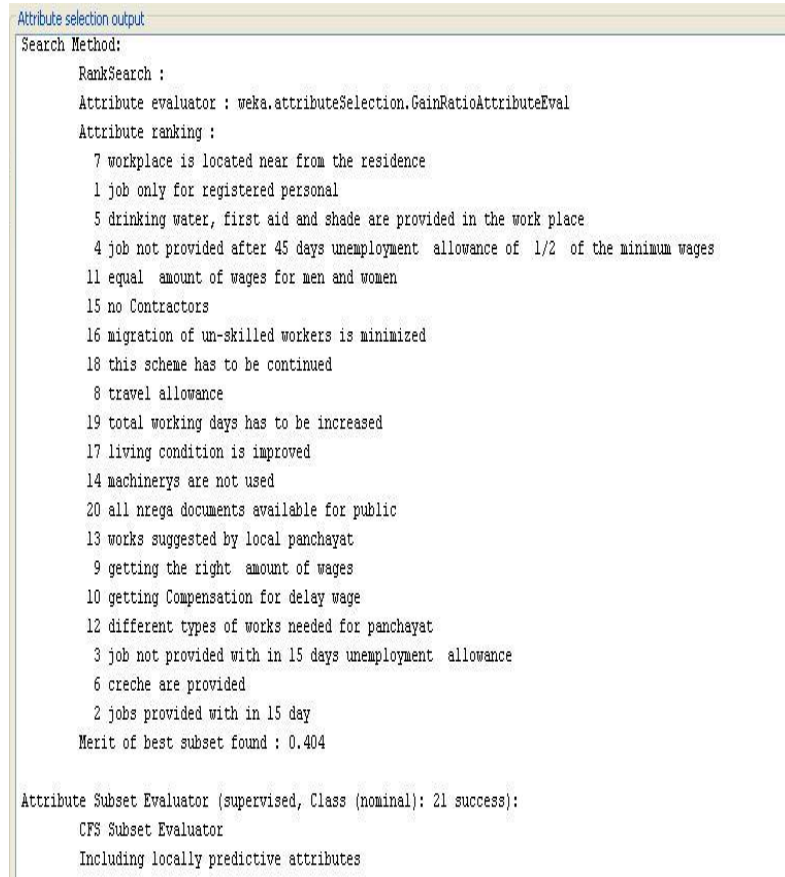

Fig 1.6 Rank Search result

Table 1.2 Results of Data mining techniques

\begin{tabular}{|c|c|c|c|}
\hline \multirow{2}{*}{ WEKA } & Navie bayes & J48 & ZeroR \\
\cline { 2 - 4 } & $97.019 \%$ & $100 \%$ & 78.0488 \\
\hline
\end{tabular}

\subsection{Performance Evaluation of}

\section{MGNREGA Scheme}

Each individual small family who are willing to work under this scheme has to register their name and get the job card. These individual families are called as House Hold. The following chart indicates the total number of job card issued in last three year. While analyzing the progress between the financial years 2012-13 and 2013-14 a slight decrease in the number of job card can be found.

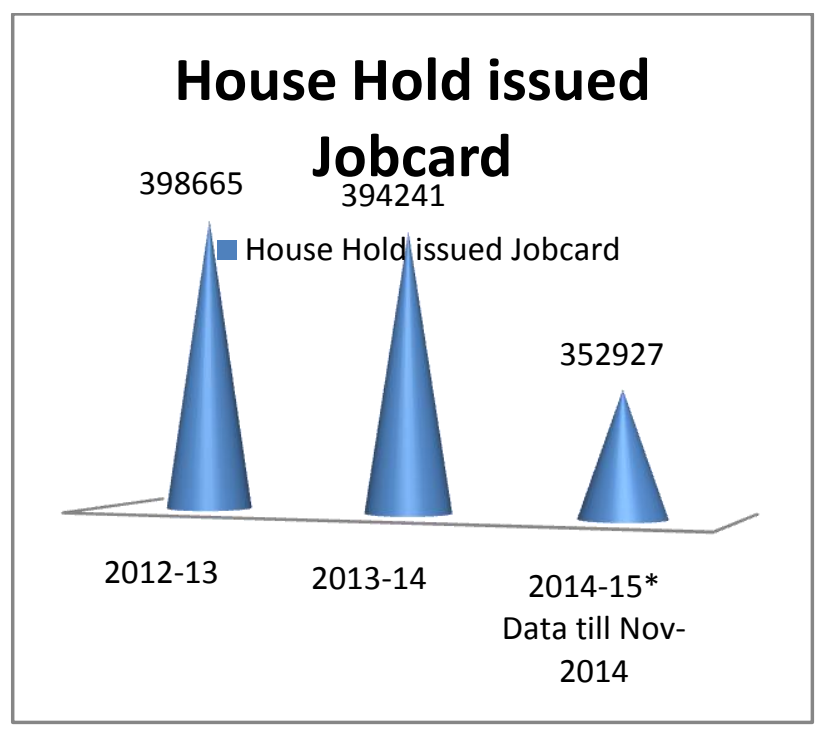

Fig 1.7 House Hold Issued Jobcard

There is a gradual decrease in the number of Employment provided for women, between the financial year 2012-13 - 
314462 and 2013-14 - 270749 although in the current financial year 2014-15 - 236503 the count seems to be increasing.

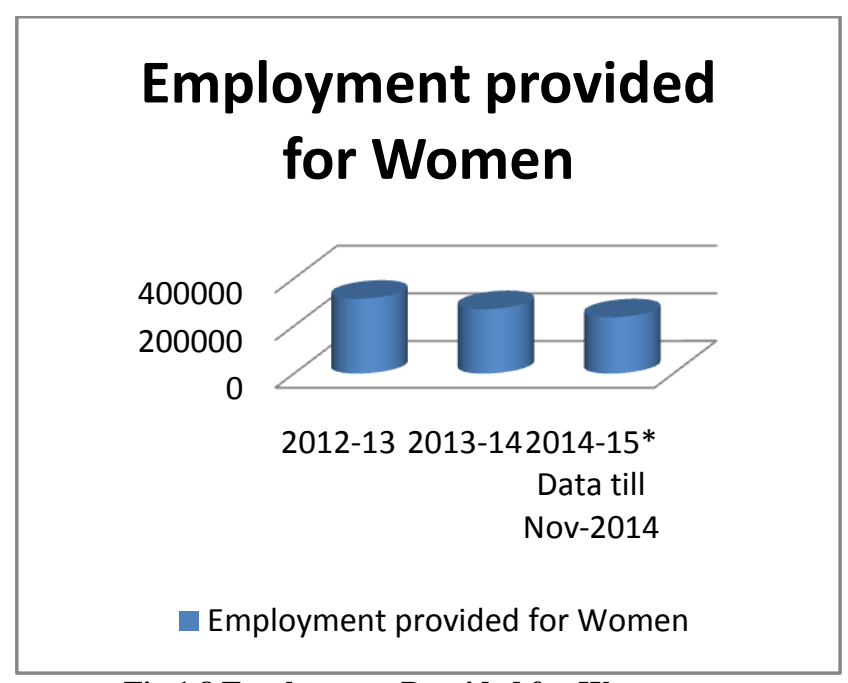

Fig 1.8 Employment Provided for Women

Person days generated is the total number of days, the entire people worked under this scheme. In the financial year 201213 the number of person days generated are 20110236, for the year 2013-14 the number of days is 18789565 and for the financial year 2014-15 it comes to 12360622 till the month of November.

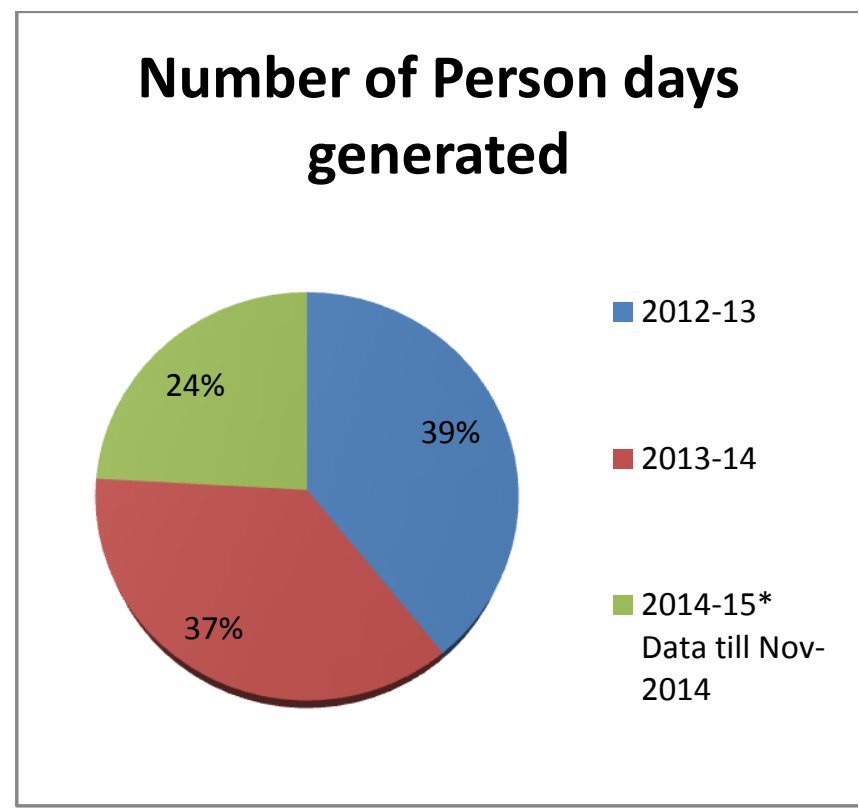

Fig 1.9 Number of Person days Generated

The following chart shows the total number of person days generated for Women. In the financial year 2012-13 the number of person days generated for women are 14994815, for the year 2013-14 the number of days counts to 15826218 and for the financial year 2014-15 till November the number came to 10588415 . Here we can find the increase in the number of women person days generated while comparing to the previous financial year.

\section{Number of Person days generated for Women}

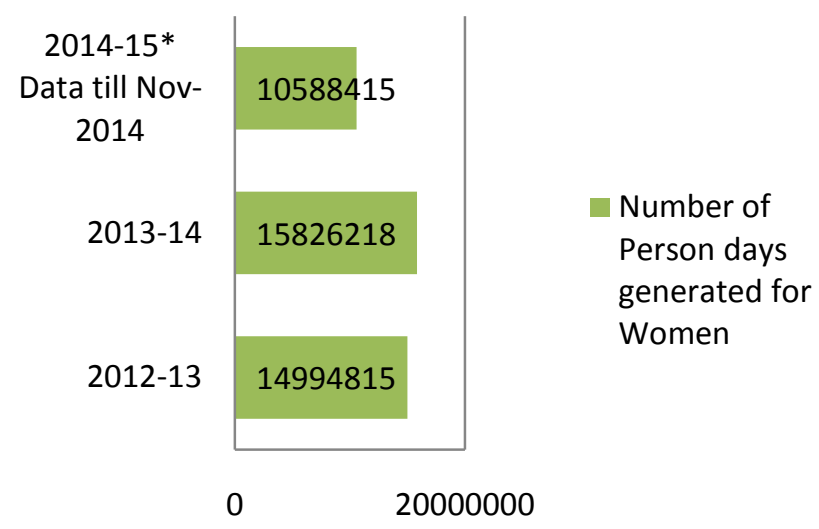

Fig 1.10 Number of Person days Generated for Women

As the result of any particular work completion Assets are created within that local body level. There are number of asserts can be created due to the nature of this scheme like tree plantation, irrigation canals, road, toilet for schools and anganwadi and solid and liquid waste management centre. The total number of assets created is keeping on increasing in each financial year from 2012-13 - 2014-15.

\section{Total Asset Created}

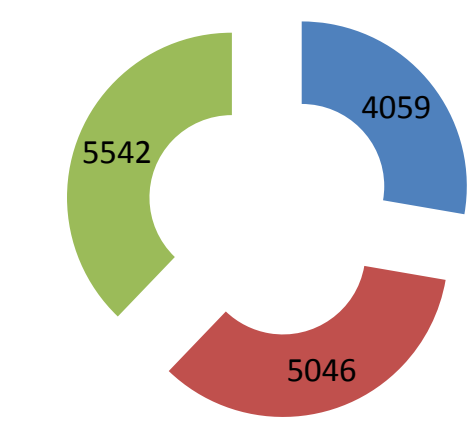

- 2012-13

2014-15*

Data till Nov2014

\section{Fig 1.11 Total Asset Created}

Employment provided for people under this scheme is kept on decreasing comparing to the previous year data. Yet the number of assert created is increasing in a remarkable way. This shows that this scheme is implemented in a proper way. The total number of employment provided for people under this scheme during the financial year 2012-13 is 472995 , for the year 2013-14 it is 373036 and for the current financial year its 296129 . 


\section{Employment provided}

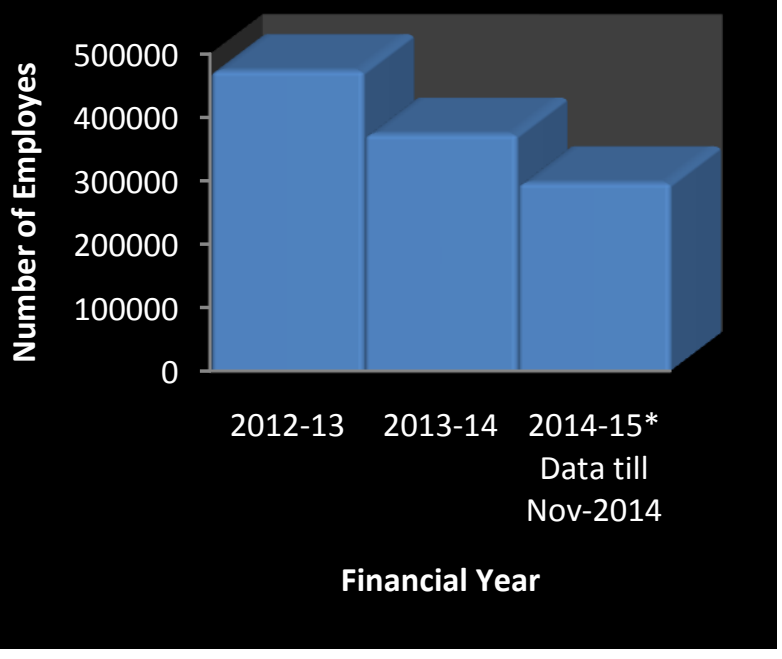

Fig 1.12 Employment Provided

\section{CONCLUSION}

MGNREGA is the major socio-economic reform scheme implemented throughout the country. Many factors are involved in the analyzing and predicting the success of this scheme. The aim of this work is to analyze the various factors involving in the process of successful implementation of this scheme. By collecting various factors which influence in the implementation part at the ground level from the employee and analyze it using weka system. Also by comparing the progress of last three financial year data, we are getting the conclusion that this scheme is potentially a success full and well designed for bringing the people above poverty line and ensuring a financial support for their family to improve the livelihood and the economic status of rural people. The major disadvantage of this scheme is it lack in the part of proper implementation in the ground level by the implementing agency.

The future scope of this work is to carry out the analysis by using various other suitable methods and by using other data mining techniques. Its scope for future work can also be extended in the part of gathering data from the implementing officials from their perspective and analyze. Hence the data collected in this paper is collected from the workers point of view.

\section{REFERENCES}

[1] S.Krishnan, Dr. A.Balakrishnan (2014), MGNREGA Marching towards achieving the millennium development goals-an analysis. Journal of International Academic Research for Multidisciplinary. Volume 2, Issue 1
[2] Soumya Mohanty, Dr. Nihar Ranjan Mishra(2012), Mahatma Gandhi National Rural Employment Guarantee Act (MGNREGA) and Tribal Livelihoods: A Case Study in Sundargarh District of Odisha.

[3] Jyoti poonia(2012), Critical Study of MGNREGA: Impact and women's participation. International Journa of Human Development and Management Sciences, Vol 1 No. 1.

[4] Abhishek Thakur, Dr. Manish K. Jha(2011), A Study on MGNREGA and its impact on wage and work relation.

[5] Vikas Chaurasis, Saurabh Pal (2014), A Novel Approach for Breast Cancer Detection Using Data Mining Techniques. Internation Journal of Innovative Research in Computer and Communication Engineering, Vol. 2, Issue 1.

[6] K. Vivekanandan, J. Soonu Aravindan(2014), Aspecbased Opinion Mining: A Survey. International Journal of Computer Applications, Volume 106- No.3.

[7] Masoud Abessi, Elahe Hajigol Yazdi(2014), Marketing Data Mining Classifiers: Criteria Selection Issues in Customer Segmentation. Volume 106-No.10.

[8] Sandeep Chaurasia, Prasun Chakrabarti, Neha Chourasis(2014), Prediction of Breast Cancer Biopsy Outcomes - An Approach using Machine Leaning Perspectives. Volume 100-No.9.

[9] A.Priyanga, S.Prakasam(2013), Effectiveness of Data Mining - based Cancer Prediction System(DMBCPS). International Journal of Computer Applications, Volume 83-No.10.

[10] Smt Pushpa Suryavanshi, Dr.H.S.G.V.V.Sagar (2014), Implementation and Impact of MGNREGA on Agriculture Produces Cost - A case study of Sagar District. Scientific Society of Advanced Research and Social Change, Volume 1 Issue 1.

[11] Bigi Thomas, Ruby Bhatia (2012), Impact of NREGA Scheme: A Study on the overall Quality of Life of Its Beneficiaries. Asia-Pacific Journal of Social Sciences, Vol.IV(2).

[12] Ashokkumar Vijaysinh Solanki(2014), Internation Journal of Computer Science and Information Technologies. Vol. 5(4).

[13] P.Yasodha, M. Kannan(2011). Analysis of a Population of Diabetic Patients Databases in Weka Tool. International Journal of Scientific \& Engineering Research Volume 2, issue 5.

[14] http://nrega.nic.in

[15] http://rural.nic.in

[16] http://planningcommisison.nic.in 